\title{
EMPREENDEDORISMO FEMININO NO NORTE DE MINAS GERAIS - ALGUMAS CIDADES, MUITAS PERSPECTIVAS
}

\section{FEMALE ENTREPRENEURSHIP IN THE NORTH OF MINAS GERAIS - SOME CITIES, MANY PERSPECTIVES}

\author{
June Marize Castro Silva* \\ Cezar Karpinsk** \\ Eline Cecília Ribeiro da Costa*** \\ Fabrícia Aparecida Gonçalves Costa*** \\ Vanessa Rodrigues Mendes*** \\ Miguel Augusto de Oliveira Neto*** \\ Edileuza Rodrigues Neve***
}

Resumo: O presente estudo tem como objetivo geral analisar as características do empreendedorismo feminino nos municípios de Brasília de Minas, Campo Azul, Icaraí de Minas, São Francisco e Várzea da Palma. E teve como objetivos específicos: identificar o perfil das empreendedoras relacionadas aos municípios base do estudo; expor os principais desafios no momento de empreender; e, apresentar as características das empreendedoras. Para tal finalidade, realizou-se uma pesquisa de natureza descritiva e abordagem quantitativa. A técnica de amostragem utilizada

\footnotetext{
* Doutorado em Ciência da Informação em andamento pelo Programa de Pós-Graduação em Ciência da Informação (PGCIN) da Universidade Federal de Santa Catarina (UFSC).

*Universidade Federal de Santa Catarina - UFSC - Programa de Pós Graduação em Ciência da Informação - PGCIN.

${ }^{* * *}$ Graduando(a) em Administração - UNIMONTES.
} 
foi a snowball, já que a indicação facilita o processo de coleta de dados. Para coletar os dados, utilizou-se como principal fonte de evidências o questionário on-line realizado por meio da plataforma Google Forms, com 179 respondentes. Com os resultados da pesquisa ficou evidenciado que o empreendedorismo feminino nas cidades de Brasília de Minas, Campo Azul, Icaraí de Minas, São Francisco e Várzea da Palma é composto em sua maioria por mulheres de 20 a 29 anos, solteiras, com curso superior completo e com filhos. Concluiu-se, portanto, que, estudos que visam entender e quantificar o papel feminino no empreendedorismo das cidades do Norte de Minas Gerais, são de grande relevância para aqueles que buscam criar um negócio e obter sua independência financeira.

Palavras-Chave: Empreendedorismo Feminino; Norte de Minas; Gênero; Trabalho.

\begin{abstract}
The general objective of this study was to analyze the characteristics of female entrepreneurship in the municipalities of Brasilia de Minas, Campo Azul, Icaraí de Minas, São Francisco and Várzea da Palma. The specific objectives were: to identify the profile of female entrepreneurs related to the base municipalities of the study; to expose the main challenges at the time of entrepreneurship; and to present the characteristics of female entrepreneurs. To this end, a descriptive research with a quantitative approach was carried out. The sampling technique used was snowball, since the indication facilitates the data collection process. To collect the data, the main source of evidence was the online questionnaire conducted through the Google Forms platform, with 179 respondents. The results of the research showed that female entrepreneurship in the cities of Brasília de Minas, Campo Azul, Icaraí de Minas, São Francisco, and Várzea da Palma is mostly composed of women between 20 and 29 years old, single, with a college degree, and with children. It was concluded, therefore, that studies that aim to understand and quantify the female role in entrepreneurship in the cities of Northern Minas Gerais are of great relevance for those who seek to create a business and obtain their financial independence.
\end{abstract}

Keywords: Female Entrepreneurship; North of Minas; Gender; Work.

Resumen: El presente estudio tiene como objetivo general analizar las características del emprendimiento femenino en los municipios de Brasilia de Minas, Campo Azul, Icaraí de Minas, São Francisco y Várzea da Palma. Y sus objetivos específicos fueron: identificar el perfil de emprendedores 
relacionados con los municipios que son la base del estudio; exponer los principales desafios en el momento de emprender; y, presentar las características de los emprendedores. Para ello, se realizó una investigación descriptiva y un abordaje cuantitativo. La técnica de muestreo utilizada fue bola de nieve, ya que la indicación facilita el proceso de recolección de datos. Para la recogida de los datos, se utilizó la principal fuente de evidencia el cuestionario online realizado a través de la plataforma Google Forms, con 179 encuestados. Con los resultados de la investigación se evidenció que el emprendimiento femenino en las ciudades de Brasilia de Minas, Campo Azul, Icaraí de Minas, São Francisco y Várzea da Palma está compuesto en su mayoría por mujeres de 20 a 29 años, solteras, con educación universitaria completa y con hijos. Se concluyó, por lo tanto, que los estudios que tienen como objetivo comprender y cuantificar el papel femenino en el emprendimiento en las ciudades del norte de Minas Gerais, son de gran relevancia para aquellos que buscan crear un negocio y obtener su independencia financiera.

Palabras clave: Emprendimiento femenino; Norte de Minas; Género; Trabajo.

\section{Introdução}

Empreendedorismo engloba o processo de criação, sinergismo e inovação. Mas para que o processo de transformação ocorra, é fundamental a canalização de esforços para assumir riscos perante as incertezas (DORNELAS, 2002). Ele atua diretamente na geração de empregos, auxiliando no desenvolvimento econômico, proporcionando a realização de uma atividade que propicie ao indivíduo uma expansão profissional, pessoal e financeira (LEAL, 2018).

Segundo Porter (1992) o empreendedorismo auxilia favoravelmente para o desenvolvimento econômico, uma vez que, contribuí para inovação de produtos ou serviços. O desenvolvimento econômico é uma vertente que por possuir uma ampla abrangência, envolve questões relacionadas às teorias econômicas, sociológicas e organizacionais. Dolabela (2002) completa, relacionando as questões voltadas para o indivíduo, pois considera que o empreendedorismo resulta de um conjunto de traços de personalidade específicos associados ao negócio. Além disso, outros aspectos emergem 
como relevantes no campo do empreendedorismo, tais como questões relacionadas ao gênero e a distinção quanto ao estilo de gestão.

Com o crescimento da participação feminina no mercado de trabalho e na gestão das empresas, o empreendedorismo feminino, está sendo considerado como um potencializador da sustentabilidade social no Brasil, conforme o Serviço Brasileiro de Apoio às Micro e Pequenas Empresas (2020).

Adentrando sobre a inserção de gênero, existem fatores contingenciais que envolvem a colocação das mulheres no mercado de trabalho. Mitos de que as mulheres possuem somente a propensão para cuidar e se ocupar do lar estão incorporados na sociedade, por outro lado, em se tratando da imagem do homem, ele é visto como provedor familiar (JONATHAN, 2001). Vale destacar que essas ideias acabam aprisionando as expectativas comportamentais vinculadas a relação entre trabalho e satisfação.

Os esforços das mulheres vêm modificando os modelos prevalentes impostos pela sociedade. Isso faz com que as mulheres tenham uma visão de diferentes perspectivas, além de trabalhar e ocupar cargos de responsabilidade, elas realizam tarefas como ser mãe, esposa e dona de casa, conquistando seu espaço provocando mudanças em padrões impregnados no decorrer da história (PROBST; RAMOS, 2003).

Diante disso, este estudo pretende apresentar, discutir e refletir sobre o empreendedorismo feminino, em especial, tendo como objetivo geral analisar as características do empreendedorismo feminino nos municípios de Brasília de Minas, Campo Azul, Icaraí de Minas, São Francisco e Várzea da Palma. Tendo como alicerce os seguintes objetivos especificos: identificar o perfil das empreendedoras relacionadas aos municípios base do estudo; expor os principais desafios no momento de empreender; e apresentar as características das empreendedoras.

Vale ressaltar que o Norte de Minas possui características singulares, nesse sentido, cada cidade é um espaço peculiar e repleto de tradições. As diversidades encontradas se expressam em aspectos sociais, culturais e econômicas (PEREIRA, 2007). 
Nessa lógica, as mulheres exercem um papel considerável no ambiente econômico, quando se adentra no assunto de empreendedorismo, as mulheres ocupam um lugar relevante. De acordo com o IBGE (2018) a proporção de mulheres $(28,2 \%)$ com trabalho a tempo parcial, sendo até 30 horas semanais, é superior à dos homens (14,1\%). Isso pode estar relacionado ao predomínio das mulheres no cuidado das pessoas e nas tarefas domésticas, sendo que as trabalhadoras despendem $73 \%$ mais tempo nesses aspectos do que os homens.

Acredita-se que tal perspectiva seja relevante, principalmente levando-se em conta que não há registro deste tipo de pesquisa nas cidades analisadas. Pode-se destacar ainda que existe carência de investigações que analisem aspectos relacionados ao gênero e as vertentes associadas ao empreendedorismo feminino e suas variáveis.

\section{Referencial Teórico}

\subsection{Empreendedorismo}

No campo da gestão empresarial, os estudos sobre o conceito de empreendedorismo vêm se tornando cada vez mais comum, de forma que seu ensino se torna cada vez mais relevante e importante em várias áreas do conhecimento (MESQUITA, 2016).

Diante da necessidade de explorar áreas ainda não buscadas, o empreendedorismo é um conceito que vem se resolvendo nas discussões acadêmicas e nas pesquisas sobre gestão. Nesse caso, o empreendedor pode se destacar, definido como um conjunto de hábitos e características pessoais que se transformam em oportunidades de negócios a partir da captura de ideias e de ações proativas (FILION, 1999).

Gartner (1990) diz que a inovação, fundação de uma organização, criação de valor, lucratividade, crescimento econômico, singularidade e, principalmente, a figura do empreendedor, são termos que descrevem o empreendedorismo. Já Schneider (2012) associa empreendedorismo a ação, a mobilização de recursos e a quem assume riscos para iniciar seus 
próprios negócios. "Aquele que se propõe a empreender é alguém que sonha e parte a concretização” (SCHNEIDER, 2012, p. 19).

De acordo com Fialho (2006) empreendedorismo nada mais é do que a capacidade de criação, estabelecendo metas e obtendo resultados positivos. Onde o objetivo a ser alcançado decorre de uma visão sistemática que não pode ser articulada com o propósito de comportamento empreendedor. O resultado vem de ação criativa, perseverança e foco nos objetivos (FIALHO, 2006).

Em concordância Scheneider (2012) diz que o empreendedorismo é uma ação realizada por determinadas pessoas que se conhecem e conhecem suas limitações, que estão dispostas a agir e a arcar com as consequências de suas ações. Na visão de Arantes (2014) o empreendedorismo refere-se à qualificação de indivíduos que estão comprometidos com suas próprias atividades de desenvolvimento de uma forma especial e inovadora. Estas atividades podem ser realizadas em uma organização, neste caso, pode caracterizar o espírito empreendedor dentro da empresa, ou pode ser uma atividade para iniciantes, ou uma atividade para pessoas que realizam sonhos. Os empreendedores inovam em qualquer área, agindo e lutando por seus próprios objetivos, e mudando suas práticas ou métodos empreendedores (ARANTES, 2014).

Na visão de Schumpeter (1978), apresentado por Arantes (2014, p. 17):

O empreendedor é o agente do processo de destruição criativa e, sendo assim, considera este como o impulso fundamental que aciona e mantém em marcha o motor capitalista, constantemente criando novos produtos, novos mercados e implacavelmente, sobrepondo-se aos antigos métodos menos eficientes e mais caros (ARANTES, 2014, p.17).

Para Filion (1999) o empreendedor tem a capacidade de definir metas claras e buscar oportunidades de negócios. É um visionário, uma pessoa que sabe usar a criatividade e o conhecimento do ambiente para aproveitar as oportunidades. Um empreendedor pode identificar oportunidades independentemente de quantos recursos ele possui, porque ele sabe como encontrar, gerenciar e capacitar recursos (DOLABELA, 2002). 
Arantes (2014) define o empreendedor como o indivíduo que percebe as oportunidades, principalmente quando se trata de aspectos relacionados a mudanças tecnológicas, dando ênfase à inovação. Neste sentido, Dolabela (2002) e Arantes (2014) salientam ser os empreendedores os motores que movem a economia, onde não são apenas movidos pelo lucro, mas também movido pelo desejo de criar. Indivíduos que inovam, descobrem e criam oportunidades de negócios, combinam e coordenam novas combinações de recursos para obter o máximo benefício da inovação (DOLABELA, 2002).

Arantes (2014) afirma que o verdadeiro empreendedor é uma pessoa interligada, intimamente ligada, atenta e dinâmica que consegue ver o que os outros não veem e produzir, mesmo quando conduz ou passa momentos de lazer com a família ou amigos. Uma pessoa que tem uma relação profunda com o seu trabalho e que não perde oportunidades, mas não prejudica a sua saúde, os seus princípios e o equilíbrio entre o corpo, o âmbito pessoal, família, interação social e profissional, levando assim o gasto de muita energia. Portanto, o empreendedor deve estar sempre preparado e utilizar todos os recursos disponiveis. Afinal, suas habilidades, aptidões e competências são decisivas em todos os momentos (ARANTES, 2014).

Reforçando a linha de pensamento, até aqui considerada, Steveson e Gumpert (1985) dizem que o desejo de mudança e crescimento, autoconsciência e capacidade de execução de metas são características de empreendedores. E seguindo esta mesma linha de raciocínio, Souza (2005) o empreendedorismo se resume em inovação, a busca de oportunidades, criatividade, propensão a correr riscos e liderança.

\subsection{Tipos de Empreendedorismo}

O conceito de Empreendedorismo pode assumir algumas vertentes que dependem de seu contexto e uso (COSTA et al. 2011). O Quadro 1 demonstra algumas definições sobre os tipos de empreendedorismo. 
Quadro 01 - Tipo de Empreendedorismo

\begin{tabular}{|c|c|c|}
\hline Tipo de empreendedorismo & Autor & $\begin{array}{r}\text { Conceito } \\
\end{array}$ \\
\hline $\begin{array}{l}\text { Empreendedorismo por } \\
\text { Necessidade e por } \\
\text { Oportunidade; }\end{array}$ & $\begin{array}{l}\text { Baggio e Kanebel } \\
\text { (2014) }\end{array}$ & $\begin{array}{l}\text { Criam-se negócios por não haver } \\
\text { outra alternativa; Ou descobrem } \\
\text { uma oportunidade de negócio } \\
\text { lucrativa. }\end{array}$ \\
\hline $\begin{array}{l}\text { Empreendedorismo } \\
\text { corporativo }\end{array}$ & Dornelas (2008) & $\begin{array}{l}\text { Empreendedorismo corporativo é o } \\
\text { processo pelo qual um indivíduo ou } \\
\text { um grupo de individuos, associados } \\
\text { a uma organização existente, criam } \\
\text { uma nova organização ou instigam a } \\
\text { renovação ou inovação dentro da } \\
\text { organização existente. }\end{array}$ \\
\hline Empreendedorismo start-up, & Gitahy (2011) & $\begin{array}{l}\text { É um modelo de empresa jovem ou } \\
\text { embrionária em fase de construção } \\
\text { de seus projetos, que está atrelada } \\
\text { fortemente à pesquisa, investigação e } \\
\text { desenvolvimento de ideias. } \\
\text { Inovadora. }\end{array}$ \\
\hline Empreendedorismo social & $\begin{array}{l}\text { Baggio e Kanebel } \\
\text { (2014) }\end{array}$ & $\begin{array}{l}\text { Produz bens e serviços para } \\
\text { solucionar problemas sociais, e não } \\
\text { para vender; não é direcionado para } \\
\text { mercados, e sim para segmentos } \\
\text { populacionais em situações de risco } \\
\text { social (exclusão social, pobreza, } \\
\text { miséria, risco de vida. }\end{array}$ \\
\hline
\end{tabular}

Fonte: elaborado pelos autores com base em Baggio e Kanebel (2014); Dornelas (2008) e Gitahy (2011).

Nesta verve, pode-se observar a diversidade de tipos e conceitos existentes, demonstrando uma área com possibilidades de pesquisas.

\subsection{Caracteristicas do Empreendedor}

Os questionamentos referentes ao empreendedorismo despertam a atenção de pesquisadores, da mesma forma, procura-se evidenciar sobre as características dos empreendedores de sucesso. Hilário (2004) elucida que na formação humana, há um conjunto de características que os indivíduos querem obtê-las, e outro conjunto, que a vida traz, sobre as mais diversas situações que o indivíduo convive.

Uma forma bastante usada de focalizar as características ou traços de personalidade esperados dos empreendedores é a partir do estabelecimento de um perfil empreendedor. É inegável que o estabelecimento do perfil é 
uma prática valorizada e disseminada. (CIELO 2001). Vale mencionar, que para Silva (2014) a identificação do perfil do empreendedor de sucesso auxilia no processo de aprender e agir.

Para Barbosa e Costa (2015) aduzem que uma das características de um bom empreendedor é a capacidade de reconhecer uma oportunidade e transformar todas as suas possibilidades e mudanças em um negócio possivel e, com isso, detectar oportunidades. Considerando essencialmente a liderança como uma das mais importantes características empreendedoras.

Nessa vertente, Hilário (2004) esclarece que dentro do processo empreendedor de busca pelo sucesso, o indivíduo deve-se contemplar diversas características pessoais básicas. Permitindo destacar a flexibilidade, a agressividade ordenada, a criatividade, a confiança e a busca para acrescentar valor para a sociedade.

Em vista disso, Barbosa e Costa (2015) e Drucker (2002) que a capacidade de assumir riscos calculados como características é importante. Admitindo-se que a intuição também é indispensável para o empreendedor.

Convém observar, que para Hilário (2004) reconhecer suas potencialidades e fraquezas reduz os riscos do negócio que eventualmente podem ser causados por ele próprio. Além do autoconhecimento, como instrumento para aprimorar os pontos já desenvolvidos e melhorar suas deficiências.

Para Mesquita (2016) e Dornelas (2016) os empreendedores de sucesso, são visionários e sabem tomar decisões, além de serem pessoas que fazem a diferença e exploram ao máximo as oportunidades, sendo determinados e dinâmicos. Por outro lado, Franco (2014) argumenta a existência de características semelhantes entre homens e mulheres. Embora, as mulheres apresentam certos aspectos, típicos da sua personalidade como a sensibilidade e a intuição. 


\subsection{Mulher e Trabalho}

A participação da mulher no mercado de trabalho formal ocorreu a partirdas I e II Guerras Mundiais, os homens iam para as batalhas e as mulheres assumiam os negócios da família. Ao final das guerras, muitos homens haviam morrido, e os sobreviventes muitas vezes ficaram mutilados e impossibilitados de trabalhar, obrigando as mulheres a deixarem suas casas e filhos para passarem a fazer o trabalho antes realizado pelos homens (PROBST, 2003 e ASSIS. 2009).

Elas eram consideradas ineficientes para assumirem uma atividade no mercado de trabalho em que os homens dominavam. Desta forma, optavam por ocupar espaços que, tradicionalmente, não eram geridos pela figura masculina (STROBINO et al., 2014).

Por outro lado, Santos et al. (2020) retrata que as diferenças entre indivíduos não são somente baseadas na estrutura anatômica de masculino e feminino, mas o desenvolvimento de ações sociais que construíram uma sociedade patriarcal, em que as mulheres eram subordinadas aos homens.

Desta maneira, o crescimento do trabalho feminino é uma dimensão importante dentre as diversas mudanças na condição das mulheres no Brasil e no mundo nas últimas décadas (ITABORAÍ, 2016).

A participação da mulher no mercado de trabalho não está somente atrelada à geração de renda, mas sim sobre a provisão dos benefícios sociais decorrentes de status mais elevado e da independência feminina (SEN, 2000).

Conforme Nogueira (2010) o trabalho doméstico é mais desvalorizado pela sociedade conservadora, por isso associam-se ao sexo feminino, entendendo que é de responsabilidade da mulher, os cuidados com a reprodução e com a manutenção da família e aos homens a produção social geral.

Franco (2014) afirma que as mulheres costumam enfrentar várias barreiras no mundo do trabalho, tais como, salários menores, deficiência 
nas políticas sociais, dificuldades na progressão de carreira, dupla jornada, falta de voz nos espaços de decisão e poder.

Nesse sentido, as mulheres encaram uma dupla jornada de trabalho, no qual, Passos (2015) esclarece ser por causa do papel subalterno e a situação de opressão vivida na família. Dessa forma, apesar das dificuldades impostas, as mulheres estão introduzidas no ambiente laboral, inclusive no trabalho por conta própria, visto que, "continuam sendo as principais responsáveis pelas atividades domésticas e pelos cuidados com os filhos e demais familiares, o que representa uma sobrecarga para aquelas que também realizam atividades econômicas" (BRUSCHINI; LOMBARDI; 2003, p. 330).

Por desempenharem diversas tarefas, "para muitas empresas, a mulher só terá disponibilidade para se dedicar plenamente ao trabalho se não tiver filhos ou se eles já forem adultos - e nesse caso ela pode ser velha demais para disputar bons e bem-remunerados postos de trabalho" (ETHOS, 2004, p. 33).

Neste sentido Brasil (2013), também mostra claramente a divisão do trabalho por gênero: em termos de desigualdade de renda, acesso a oportunidades de carreira e jornada de trabalho dobrada, estas têm acumulado trabalho produtivo e reprodutivo. As tarefas familiares e de cuidado ainda são predominantemente femininas, o que tem diversos efeitos sobre a possibilidade de emprego e outras atividades, como educação, participação em associações e partidos politicos, lazer e autocuidado (VICENTE, 2018).

Devido ao efeito combinado de vários fatores, Bruschini, Ricoldi e Mercado (2008) dizem que as mulheres entraram nessas ocupações de alta qualidade. Entre elas, a partir do final da década de 1960, principalmente na década de 1970, com as intensas transformações culturais dos movimentos sociais e políticos daquela década, as mulheres foram incentivadas a ingressar na universidade em busca de uma carreira.

Neste contexto, elucida-se que as mulheres avançaram no que se refere à conquista de espaço no mercado de trabalho, crescendo em 
diversos setores e atualmente concilia as atividades profissionais com papéis familiares.

As mulheres buscam a construção de sua autonomia, dessa forma contribui para a edificação do desenvolvimento social.

\subsection{Empreendedorismo Feminino}

A participação da mulher no mercado de trabalho vem carregada de mudanças nas ocupações e nas relações sociais, culturais, demográficas e econômicas. Sendo assim, permite-se observar uma participação crescente delas no empreendedorismo, Franco (2014) define que as mulheres reconhecem no empreendimento a oportunidade de vida mais promissora, relativa à busca por crescimento profissional e realização pessoal.

Por outro lado, Strobino apud Gomes e Santana (2014) afirmam que uma das razões para que a mulher venha a ter seu próprio negócio é a flexibilidade de horários, de forma que ela acredita que poderá compatibilizar trabalho e família, oferecendo mais autonomia na perspectiva feminina.

Ademais, Franco (2014) afirma que as mulheres empreendem mais por necessidade do que por oportunidade, visualizando uma estratégia de vida e não apenas uma ocupação.

Diante disso, qualquer tentativa de criação de um novo negócio ou novo empreendimento, como por exemplo, uma atividade autônoma, uma nova empresa, ou a expansão de um empreendimento existente. Em qualquer das situações a iniciativa pode ser de um indivíduo, grupos de indivíduos ou por empresas já estabelecidas (GEM, 2010, p. 215).

"A ação de empreender é vista como prática de aprendizado - que envolve imaginação, criatividade, exploração do desconhecido e engajamento e de oportunidade" (CAMARGO et al., 2008, p.109).

Álvarez e Timóteo (2013) destaca que, embora o movimento feminista faça parte do movimento mais amplo de mulheres, destaca-se por defender os interesses de gênero das mulheres, questionar o sistema cultural e 
político construído por mulheres historicamente dotadas de papéis de gênero e definir sua autonomia em relação aos outros.

Segundo Silva (2007), a mulher tem ganhado cada vez mais importância estratégica, pois a diversidade, processos multifuncionais, compartilharmos experiências e habilidades com a empresa ou sua equipe.

A sociedade, segundo GEM (2010), tem diferentes visões e costumes sobre o trabalho das mulheres e sua participação nos negócios. Diferentes niveis de educação e desenvolvimento podem influenciar muito as crenças sociais, que geralmente estão relacionadas ao grau de aceitação ocupacional feminina. No entanto, em alguns casos, as mulheres investem no empreendedorismo independentemente de suas opiniões ou simplesmente porque sua família precisa de renda. Além disso, a aceitação social de deixar os filhos em creches para o desenvolvimento de uma carreira, juntamente com o custo da prestação de serviços para esse fim, pode ter um impacto significativo (GEM,2010).

"A mulher empreendedora também necessita da cooperação e apoio de investidores e financiadores, empregados, fornecedores e consumidores, conforme GEM (2010, p.46). E existe uma "Corporação Financeira Internacional (IFC), por meio do programa Banking on Women, que trabalha com parceiros e instituições financeiras em todo o mundo, de forma rentável e sustentável, para auxiliar empresas gerenciadas por mulheres a se desenvolverem" (SEBRAE, 2014).

\section{Método}

A pesquisa caracteriza-se como bibliográfica. As informações relacionadas ao tema e o segmento estudado foram explicadas por meio de referências teóricas publicadas em artigos, livros e teses. Para Marconi et al. (2010) a pesquisa bibliográfica coloca o pesquisador em contato direto com tudo que foi escrito, dito ou ainda filmado sobre determinado assunto.

Da mesma forma, aborda a pesquisa descritiva que impõe ao investigador uma série de informações referentes ao que deseja pesquisar. 
Vergara (1998) elucida que a pesquisa descritiva expõe características de determinada população ou de determinado fenômeno.

De abordagem quantitativa, fez-se uso da técnica de questionário virtual através do Google Forms, e a análise dos resultados foi realizada mediante o formato de gráficos originados dos dados coletados. Marconi et al. (2010) salientam que o enfoque quantitativo objetiva levantar os dados fundamentando em dados numéricos, buscando, especialmente, por informações e atributos mensuráveis da experiência humana. Nesse sentido, procura-se levantar dados sobre o grupo que constitui o objeto de estudo buscando estabelecer um panorama sobre os aspectos pessoais e profissionais das empreendedoras.

O cenário escolhido para a realização do trabalho foram as cidades de Brasília de Minas, Campo Azul, Icaraí de Minas, São Francisco e Várzea da Palma, tendo como sujeito da pesquisa as empreendedoras que atuam em diversos segmentos de negócios.

Inicialmente, visando a identificação das participantes foi utilizada a técnica metodológica snowball, traduzida como "bola de neve" ou "amostragem em bola de neve" ou ainda "cadeia de informantes" (Souza et al., 2017), já que a indicação facilita o processo de coleta de dados, onde umas indicaram as outras. Com isso, foi possivel identificar empreendedoras para enviesar a pesquisa que concerne o empreendedorismo feminino nos municípios citados.

Para coletar os dados, utilizou-se como principal fonte de evidências o questionário on-line realizado por meio da plataforma Google Forms, onde obteve 205 respondentes, sendo 179 validadas, no período de 13 a 29 de abril do ano de 2021 e em sua composição continha perguntas fechadas, isto é, objetivas. O envio do formulário de se deu através do WhatsApp.

O questionário enviado às empreendedoras foi dividido em três partes: a primeira com o intuito de coletar informações pessoais sobre elas, a segunda com a finalidade de conhecer um pouco mais sobre seus respectivos negócios, e a terceira com o propósito de identificar quais os efeitos que a pandemia trouxe para o seu empreendimento. 


\subsection{Unidades de Pesquisa}

Para maior compreensão do cenário onde foi realizada a pesquisa, seguem-se algumas informações sobre as unidades de pesquisa.

Tabela 1 - População em milhares de pessoas

\begin{tabular}{lrrr}
\hline \multicolumn{1}{c}{ Cidade } & $\begin{array}{c}\text { População } \\
\text { Censo } \\
\mathbf{2 0 1 0}\end{array}$ & $\begin{array}{c}\text { População } \\
\text { estimada } \\
\mathbf{2 0 2 0}\end{array}$ & $\begin{array}{c}\text { Densidade } \\
\text { demográfica } \\
\text { (hab/km) }\end{array}$ \\
\hline Brasília de Minas MG & 31.213 & 32.405 & 22,3 \\
Campo Azul MG & 3.684 & 3.824 & 7,28 \\
Icaraí de Minas MG & 10.746 & 12.097 & 17,18 \\
São Francisco MG & 53.828 & 56.477 & 16,27 \\
Várzea da Palma MG & 35.809 & 39.803 & 16,13 \\
\hline
\end{tabular}

Fonte: IBGE, 2021.

Dos municípios analisados o mais populoso é São Francisco com 56.477 habitantes e o menos populoso é Campo Azul com 3.824 habitantes. Na Tabela 2, pode-se observar em Campo Azul a média de salário dos trabalhadores se apresenta mais baixa em relação aos demais. E neste sentido destaca-se Várzea da Palma com 1,9 salários. Outro dado que chama a atenção é o número de pessoal ocupado, neste quesito o município de Icaraí de Minas possui o menor percentual com 4,2\%.

Tabela 2 - Trabalho e rendimento

\begin{tabular}{lcccc}
\hline \multicolumn{1}{c}{ Cidade } & $\begin{array}{c}\text { Salário médio } \\
\text { trabalhadores } \\
{[\text { [2018] }}\end{array}$ & $\begin{array}{c}\text { Pessoal ocupado } \\
{[\mathbf{2 0 1 8}]}\end{array}$ & $\begin{array}{c}\text { População } \\
\text { ocupada } \\
{[\mathbf{2 0 1 8}]}\end{array}$ & $\begin{array}{c}\text { População com } \\
\text { rendimento até } \\
\mathbf{1} \text { : salário } \\
{[\mathbf{2 0 1 0}}\end{array}$ \\
\hline Várzea da Palma - MG & 1,9 & 5.677 pessoas & $14,5 \%$ & $40,6 \%$ \\
Brasilia de Minas-MG & 1,7 & 3.501 pessoas & $10,8 \%$ & $48,8 \%$ \\
Icaraí de Minas - MG & 1,6 & 504 pessoas & $4,2 \%$ & $52,3 \%$ \\
São Francisco-MG & 1,8 & 4.177 pessoas & $7,4 \%$ & $49,2 \%$ \\
Campo Azul-MG & 1,5 & 359 pessoas & $9,4 \%$ & $51,1 \%$ \\
\hline
\end{tabular}

Fonte: IBGE, 2021. 
Como esta pesquisa busca analisar o empreendedorismo feminino nos municípios citados, outra informação importante é o quantitativo de homens e mulheres, neste sentido na Tabela 3 observa-se que apesar de existir uma prevalência do sexo masculino, embora a diferença entre estes em todos os municípios é baixa.

Tabela 3 - População de Homens e Mulheres

\begin{tabular}{lrr}
\hline \multicolumn{1}{c}{ Cidade } & Homens & Mulheres \\
\hline Brasília de Minas - MG & 15.597 & 15.624 \\
Campo Azul - MG & 1.947 & 1.738 \\
Icaraí de Minas - MG & 5.556 & 5.181 \\
São Francisco - MG & 27.313 & 26.585 \\
Várzea da Palma - MG & 18.144 & 17.660 \\
\hline
\end{tabular}

Fonte: UOL, 2021.

As informações dos municípios pretendem contextualizar a região, demonstrando ainda mais a relevância deste estudo.

\section{Análise e Discussão dos Resultados}

Neste tópico serão apresentadas as constatações da pesquisa realizada nas cidades de Brasília de Minas, Campo Azul, Icaraí de Minas, São Francisco e Várzea da Palma, junto as empreendedoras destes municípios.

Quanto a localidade de vinculação das empreendedoras, constatase uma prevalência do municipio de Brasília de Minas com $25 \%$ de participantes, o município de Várzea da Palma com 20\%, Campo Azul com $20 \%$ de respondentes, Icaraí de Minas com 18\% e por último São Francisco com um total de $17 \%$ de empreendedoras que participaram da pesquisa. Em função dos números apresentados, cabe salientar que a proporção dos dados não é em função do tamanho das cidades, ou de sua população.

Buscando-se conhecer o perfil das empreendedoras, questionou-se a idade, e neste sentido percebeu-se que as mulheres analisadas começaram a empreender mais cedo, 37,4\% têm idade entre 20 e 29 anos, seguido de $34,6 \%$ as mulheres com idade entre 30 e 39 anos. Estas informações 
são distintas das apresentadas por, Da Silva et al. (2016) onde 60\% das respondentes tinham entre 30 e 49 anos. E a pesquisa de Machado et al. (2003) onde a maior incidência foram mulheres com idade entre 41 e 50 anos, sendo um total de 37,78\% nos três países envolvidos, sendo Brasil, Canadá e França. Percebe-se que os dados da pesquisa em questão mostram uma realidade diferente nas cidades pesquisadas, demonstrando um diferencial nos perfis.

Observando-se o estado civil, é possivel constatar a predominância das mulheres solteiras, perfazendo um total de 40,8\% das empreendedoras, seguidas de 35,8\% casadas. Além disso, 13,4\% delas estão em união estável, no qual configura uma terminologia nova, menos formal que o casamento, mas reconhecida pelo Art. 1723 do Código Civil Brasileiro (FERNANDES, 2020). Por outro lado, autores como Loiola (2016) e Fernandes et al (2016) constataram em suas pesquisas uma predominância de empreendedoras casadas, novamente constata-se uma realidade distinta da amostra deste estudo nas cidades norte mineiras.

Buscando aprofundar e conhecer o perfil das empreendedoras, verificase que a maioria são escolarizadas, sendo $36,3 \%$ superior completo, 35,2\% médio completo e 12,8\% superior incompleto. Jonathan (2005) classificou as empreendedoras da sua pesquisa como sendo altamente escolarizadas, onde a maioria apresentou nivel superior completo, sendo um total $61,2 \%$ com formação entre as áreas de humanas, social e médica.

Acerca da quantidade de filhos, constatou-se que 47,5\% das entrevistadas possuem de 1 a 2 filhos, já 36,3\% não possuem filhos, seguido de 13,4\% que apresentam de 3 a 4 filhos. Dessa forma, percebese o percentual relevante das mulheres que detém de 1 a 2 filhos. Este resultado, corrobora com o estudo de autores como Machado (2013) citados Bonfim et al (2015) em que a maioria das empreendedoras possuem no minimo 1 filho.

Em relação ao segmento do negócio, nos dados obtidos pode-se constatar que as empreendedoras estão inseridas no comércio de vestuário com 23,6\%, seguido de 15,8\% nos empreendimentos de salão de beleza e $9,7 \%$ no ramo de cosméticos, os demais percentuais encontramse pulverizados em segmentos empreendidos. Além disso, o resultado 
demostra, que possivelmente, as oportunidades de negócios voltadas para o público feminino e que são administrados por mulheres, ocorrem em função destas atividades terem sido por muito tempo atividades atribuídas a elas (PESSOA, 2015).

Quando questionadas em relação ao tempo à frente de seus negócios, os resultados obtidos mostram uma equivalência de $30,2 \%$ para mais de cinco anos, seguido de $27,4 \%$ de 3 a 5 anos, $25,7 \%$ de 1 a 2 anos e $16,8 \%$ de seis meses a 1 ano. Torna-se possivel a constatação de que há um equilíbrio entre quem está a mais tempo no mercado e aquelas que estão ingressando, isto demonstra solidez do empreendedorismo liderado pela figura feminina. Embora as mulheres venham lutando por igualdade e espaço no mercado de trabalho, estar à frente de um negócio e mantêlo ativo requer muito dinamismo para os desafios a serem enfrentados (SIQUEIRA, 2017). Nesse sentido, o Sebrae (2018) divulgou uma pesquisa realizada pelo IBGE no qual mostra as mulheres à frente dos negócios no Brasil, ultrapassando os 9 milhões em 2018, deixando o país em sétimo lugar no ranking de proporção de empreendimentos iniciais, ou seja, com 3, 5 anos de existência.

Em relação a renda familiar $66,5 \%$ das empreendedoras afirmaram que o seu negócio não é a única fonte de renda da família, ou seja, grande maioria tem iniciado seus negócios para complemento da renda em casa. Este indicador corrobora com Aveniet al. (2012) que concluiu que as mulheres têm empreendido para complementar a renda familiar.

O Gráfico 1 a seguir representa a renda familiar das empreendedoras:

\section{Gráfico 1 - Renda familiar}

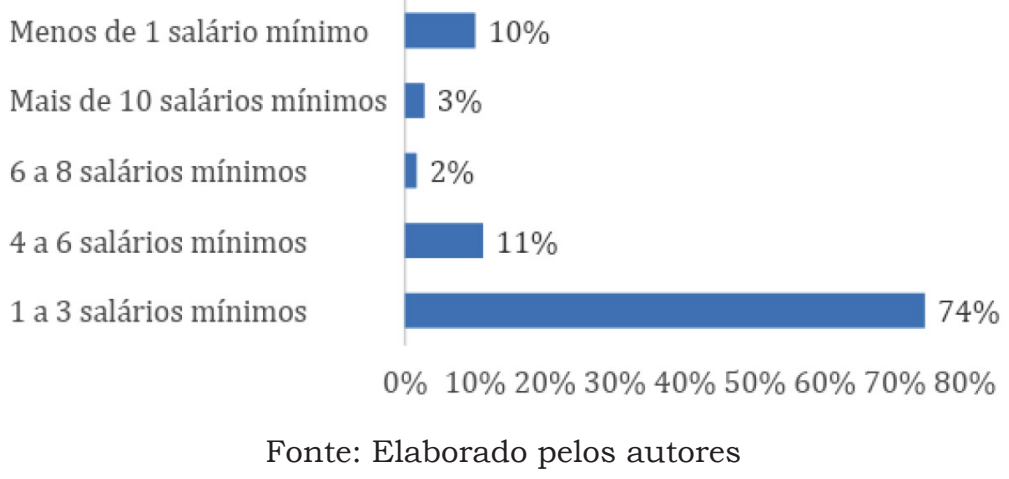


Conforme a pesquisa, percebeu-se que a maioria das mulheres tem uma renda de um a três salários-minimos, com $74 \%$ e $11 \%$ quatro a seis salários-mínimos, seguido de $10 \%$ que tem a renda equivalente a menos de um salário mínimo. Da Silva et al. (2016) afirma que os salários das empreendedoras são baixos. Na sua pesquisa 39 mulheres disseram ter uma renda entre um e três salários-mínimos, e 36 disseram ter entre quatro e dez salários-mínimos. Os dados são compativeis com a amostra em questão, onde a maior parte das empreendedoras obtém uma renda até três salários. Contudo, considerando o baixo custo de vida e a realidade das cidades pesquisadas, esse não é considerado um salário baixo e sim compativel.

Em termos de apoio ao processo de empreender, constatou-se que o maior apoiador do empreendimento das mulheres são os esposos/ companheiros com 39,1\% das respostas, 25,7\% indicaram os pais como os principais apoiadores e 12,3\% mencionaram os filhos. Os dados validam a pesquisa de Da Silva et al. (2016) onde as respondentes optaram respectivamente pelo esposo/companheiro, pais e filhos. Em resumo, a família é um grande incentivo para as mulheres, principalmente os companheiros que vem se mostrando importantes no apoio e na coordenação dos empreendimentos femininos.

Buscou-se também conhecer sobre o início do empreendimento, as respostas mais predominantes foram que 60,1\% das empreendedoras começaram o negócio sozinha, 20,8\% iniciaram seu negócio com o esposo/ companheiro e outras $14 \%$ disseram que começaram com um membro da família. Observa-se diante dos dados obtidos que as maiorias das entrevistadas abriram o negócio sozinha um fato que explica essa questão é que as empreendedoras buscam cada dia mais se tornar independentes. Conforme a pesquisa de Welsh et al. (2013), constatou que aproximadamente metade das mulheres (42\%) começam seu negócio sozinhas, seguidas de $42 \%$ com outras pessoas e um baixo percentual (9\%) herança familiar.

Em relação ao financiamento, 69,8\% das mulheres utilizaram fonte própria para iniciar seu empreendimento, seguido de 16,8\% que utilizaram empréstimo familiar. Na pesquisa de Da Silva et al. (2016) os dados são coerentes, eles constatam que, a maior parte das mulheres desenvolveram 
seu negócio com fonte própria. Observa-se também que a maioria das mulheres têm receio em pegar empréstimos bancários. Machado et al. (2003) apontou que apenas $10 \%$ das mulheres utilizaram o empréstimo bancário como origem de recursos, já na amostra de estudo o total de mulheres que utilizaram empréstimo bancário foi de $8,4 \%$, sendo percentuais bastante similares. Em geral, observa-se que as mulheres estão desenvolvendo seus empreendimentos por iniciativa e fonte própria.

Acerca dos principais motivos que levaram as empreendedoras a criarem o seu negócio, esta questão buscou analisar o grau de importância das respondentes com os motivos listados. A questão relacionada ao aumento de renda foi predominante com $87,7 \%$ indicando que as mulheres iniciaram seus empreendimentos com o objetivo de complementar a renda em casa. Assim como nos estudos realizados por Aveni et al. (2012) o objetivo das mulheres é a complementação da renda familiar. Outro motivo predominante foi o desejo de ser independente e ter o próprio negócio, onde $85,5 \%$ indicaram este como sendo o motivo principal. Da Silva et al. (2016) aduzem que as mulheres estão buscando ser independentes e ter sua própria fonte de renda. Na sua pesquisa a maior parte das respondentes está à frente das suas organizações sendo majoritárias em seus empreendimentos.

Em relação com a identificação de uma oportunidade de negócio, 76\% das mulheres afirmaram ser esse o motivo inicial do seu empreendimento. Machado et al. (2003) afirmam que a realização pessoal, a oportunidade de mercado, os problemas com o emprego anterior, são fatores fundamentais para que as empreendedoras criem seus negócios. Na pesquisa em questão, $34,1 \%$ das mulheres mencionaram a insatisfação com o emprego e 49,7\% disseram que o desemprego foi o motivo impulsionador para criação do negócio. Em resumo, os fatores que motivaram as mulheres a empreender são complexos e variados. Jonathan (2011) relata na sua pesquisa que os principais motivos que impulsionam as mulheres a empreender são a auto realização, a busca por independência e estabilidade financeira. Desta forma, as mulheres buscam desenvolver seu potencial pessoal, profissional, exercer a capacidade de decisão e formas de agir no empreendedorismo.

Quando indagadas sobre os principais conflitos existentes na realização do negócio, $52 \%$ das empreendedoras responderam que conciliar 
trabalho, família e vida pessoal é o maior enfrentamento vivido por elas. Do total, 36,3\% responderam conciliar trabalho e familia, e 11,7\% conciliar trabalho, tarefas domésticas e cuidar dos filhos. Os resultados sugerem que os conflitos são gerados devido aos múltiplos papéis que a mulher precisa conciliar, seja como esposa, mãe, figura feminina que, mesmo a frente de seu empreendimento precisa, ainda enfrentar os contratempos com os afazeres do lar (ALPERSTED et al., 2014). Pode-se observar que o estudo ratifica as discussões de Rodrigues (2020) ao salientar que as tarefas e obrigações das mulheres atualmente, se comparado a outras épocas, tem aumentado, visto que desempenham as novas funções, mas não se isentam das atividades que lhes eram exigidas anteriormente.

Ao analisar a dedicação das mulheres para consigo mesmas. Das empreendedoras analisadas, 32,4\% afirmaram ter em média três horas para cuidarem de si. As mulheres vêm adotando estratégias para conciliar trabalho e vida pessoal, como por exemplo não levar trabalho para casa e garantir um tempo para dedicarem a si mesmas (ROCHA; COUTINHO, 2003). Outras $11,2 \%$ das respondentes afirmaram ter menos de uma hora para cuidar de si mesma. Jonathan (2011) aduz que as mulheres possuem uma carga horária de trabalho pesada, e que isso acarreta no lazer prejudicado, pouco tempo para a família e para si mesma. É perceptível que as empreendedoras buscam administrar o tempo da melhor forma possivel.

Ao verificar quanto tempo às empreendedoras pesquisadas trabalham por dia, as respostas obtidas foram que 33,5\% trabalham mais de 08 horas por dia, 30,7\% das entrevistadas declararam que trabalham até 08 horas por dia, 25,1\% delas trabalham 06 horas por dia, e outras 10,6\% afirmam trabalhar durante um periodo de 04 horas por dia. De acordo com a literatura, uma dos motivos que influência a mulher a ter o seu próprio negócio é a flexibilidade de horários, acreditando em poder conciliar o trabalho e também tempo para cuidar da família, (GOMES; SANTANA, 2004), contudo isso significa que apesar de a maioria das entrevistadas declararem que trabalham por um período maior de tempo as empreendedoras conseguem fazer uma flexibilização dos horários, além de conseguir cuidar da família, proporciona a elas a oportunidade de oferecer as clientes horários flexiveis.

Das empreendedoras analisadas, um percentual de 74,3\%, possui ajudante para os serviços domésticos ou cuidados com os filhos. Para 
Moreira (2018), esse fato se justifica levando em consideração que mulheres bem-sucedidas tendem a delegar boa parte de suas tarefas a seus colaboradores e preferem dividir suas funções, sejam elas profissionais ou domésticas, a eliminar ou diminuir seus encargos, evitando a sobrecarga de suas atividades no dia a dia. No entanto, Teixeira (2016) confronta a ideia de Moreira ao afirmar que, algumas mulheres empreendedoras não designam as atividades da casa ou cuidado com os filhos a terceiros, por disporem de autonomia para flexibilizar seus horários e compatibilizar o trabalho, casa e família, justificando assim o percentual de $25,7 \%$ que não tem ajudante em casa.

Como forma de gerenciar os conflitos, $34,1 \%$ das respondentes trabalham em casa, 25,1\% indicaram outras alternativas, 22,3\% moram próximo ao trabalho, 12,8\% compartilham o cuidado dos filhos com a mãe/ sogra. Este resultado evidencia o fato de que ser dona do próprio negócio, conforme afirma Moreira (2018), acarreta algumas vantagens, como exemplo, trabalhar em casa, de acordo com o tipo de empreendimento. Além disso, terceirizar os cuidados dos filhos é outra estratégia adotada para conciliar o negócio com a maternidade.

\section{Gráfico 2 - Ferramentas de atualização}

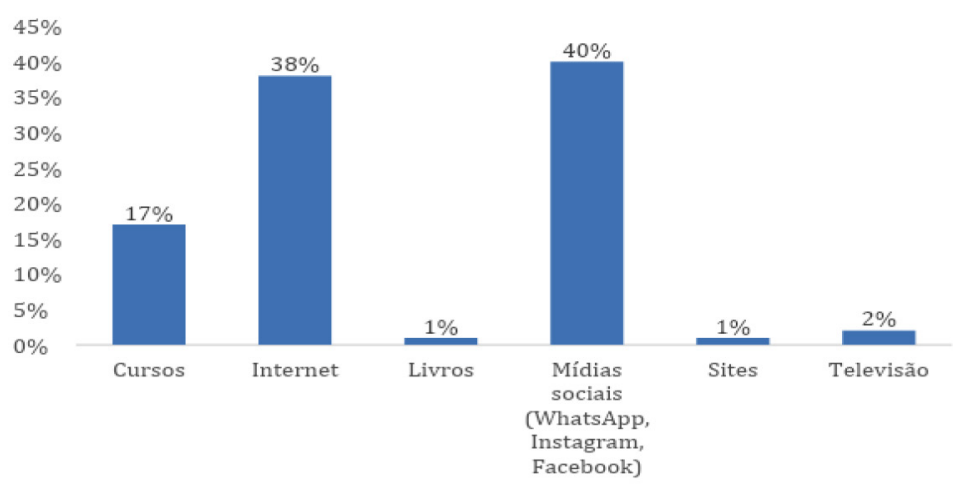

Fonte: Elaborado pelos autores (2021)

No Gráfico 3 buscou-se conhecer como as empreendedoras se mantém atualizadas com relação aos negócios, das respostas obtidas $40 \%$ responderam que usam mídias sociais como Whatsapp e Instagram, 38\% utilizam a internet e $17 \%$ optam por especializações por meio de cursos. 
Já 2\% acompanham a televisão para se manterem atualizadas. Pode-se perceber diante das respostas obtidas que as entrevistadas utilizam como principal fonte para se manter atualizada o uso das redes sociais e a internet, os dados obtidos em campo acabam por confirmar aquilo que é preconizado na literatura. De acordo com Brandão (2016) as redes sociais têm um papel excepcional na vida das mulheres empreendedoras, pois tem sido ferramentas para divulgar e realizar suas vendas nas redes com o marketing digital, atendendo sem depender do seu local de empreendimento.

Considerando ainda o momento da realização da pesquisa, foi necessário levar em consideração a pandemia COVID-19, que impulsionou o crescimento do marketing digital. Assim, Shuler (2020) destaca a convicção de que a busca por se reinventar é uma questão de sobrevivência e rever estratégias é um caminho a seguido neste momento desafiador. Diante desse cenário muitos negócios sofreram impactos em seu funcionamento, exibindo trajetórias marcadas por vários desafios. Dessa forma, dos empreendimentos liderados por mulheres é possível verificar a predominância em relação à redução de vendas, no alcance de 63,1\%. Em seguida, está a perda de clientes no percentual de 55,3\%, o acesso ao cliente resultou em 50,8\%. As doenças causadas pela pandemia tiveram relevância de $47,5 \%$ de acordo com o gráfico. As mulheres também se sentiram desanimadas com o momento vivido conforme mostra o percentual de 45,3\%. Constata-se que o acesso aos fornecedores de produtos resultou em uma pertinência de 40,2\% das respostas. Corroborando com os resultados, Locatelli (2020) afirma que esse ambiente de incertezas gerado por esta crise, resulta em uma tendência de quedas nos índices de consumo e, consequentemente, reduz-se as vendas e as pessoas ficam mais cautelosas com os gastos econômicos.

\section{Considerações Finais}

Com os resultados pode-se concluir que o empreendedorismo feminino nas cidades de Brasília de Minas, Campo Azul, Icaraí de Minas, São Francisco e Várzea da Palma é composto em sua maioria por mulheres de 20 a 29 anos, solteiras, com curso superior completo e com filhos. 
$\mathrm{Na}$ amostra analisada os empreendimentos estão divididos em sua maior parte nas áreas de comércio de vestuários, seguidos por empreendimentos em salão de beleza e na venda cosméticos. A maioria das mulheres relatam que iniciaram o negócio com o propósito de complementar a renda familiar, e que para isso recebiam apoio dos maridos ou pais e filhos. O desemprego é um dos fatores que impulsionaram a abertura dos seus negócios. A utilização de mídias sociais e internet é o meio de divulgação dos seus trabalhos que garantem maior visualização do seu produto e serviço.

A possibilidade de trabalhar em casa é um dos fatores que caracteriza o negócio liderados por mulheres, já que são necessárias mais 8 horas de trabalho e elas precisam flexibilizar o seu horário com os demais a fazeres domésticos e com os filhos. Apesar de algumas mulheres da pesquisa indicarem que possuem ajudante para os serviços domésticos.

A pandemia do Covid-19 representou o maior entrave nos negócios femininos, com redução de vendas e desanimo entre as empreendedoras com relação a doença e o efeito nas pessoas e na sociedade de maneira geral.

Com isso, conclui-se que há maior participação de jovens mulheres no cenário empreendedor. E que a necessidade da abertura de negócio se dá para obtenção de complementação de renda e independência financeira, com utilização da internet e de suas mídias sociais para manter a divulgação do produto e serviços.

Estudos que visam entender e quantificar o papel feminino no empreendedorismo das cidades do Norte de Minas Gerais, são de grande relevância para aqueles que buscam criar um novo negócio e obter sua independência financeira.

Por isso, mais estudos são necessários em outras cidades do Norte de Minas Gerais, para que se obtenha uma representatividade maior do número de negócios liderados por mulheres, quais os próximos projetos que estas empreendedoras possuem e conselhos que elas dariam para quem deseja iniciar como donas do próprio negócio. Além disso, o estudo foi limitado há apenas cinco cidades do Norte de Minas. 


\section{Referências}

ALPERSTEDT, G.D.; FERREIRA, J.B.; SERAFIM, M.C. Empreendedorismo feminino: dificuldades relatadas em histórias de vida. Revista de Ciências da Administração, v.16n. 40, p. 221-234,2014.

ÁLVAREZ, Sonia. Engendering democracy. In.: Brasil: women's moviments in transition politics. Pincenton: Princeton University Press, 1990.

ARANTES, Eliane Cristina. Empreendedorismo e responsabilidade social. [livro eletrônico] / Elaine Cristina Arantes, Zélia Halicki; Adriano Seadler (Org). 2 ed. Ver. - Curitiba: InterSaberes, 2014.

ASSIS, R.H.A. Inserção da mulher no mercado de trabalho. In: convibra.com. br. 2009. Disponivel e<http//www.convibra.com.br/2009/artigos/140_0. pdf.> Acesso: 06 jun. 2021.

AVENI, Alessandro; NUNES, M. Sc Carlos Neymer F.; CRUZ, M. Sc Lucineide AM. Um estudo do comportamento de mulheres empreendedoras no Distrito Federal. 2012.

BAGGIO, Adelar Francisco; KNEBEL ,Daniel. Empreendedorismo: Conceitos e definições. Revista de Empreendedorismo, Inovação e Tecnologia, Passo Fundo, v. 1, n. 1, p. 25-38, jan. 2014. ISSN 2359-3539.

BARBOSA, Lucas Oliveira, COSTA, Túlio Vieira Bassi. Perfil empreendedor: Um estudo sobre as características do perfil empreendedor. UFF, Volta Redonda-RJ, 2015

BONFIM, Lea Cristina Silva; TEIXEIRA, Rivanda Meira. Empreendedorismo feminino: Desafios enfrentados por empreendedoras na gestão de pequenos negócios no setor de turismo. Revista Pensamento Contemporâneo em Administração, vol. 9, núm. 2, abril-junho, 2015.

BRASIL. Presidência da República. Secretaria de Politicas para as Mulheres. Plano Nacional de Politicas para as Mulheres. Brasília: Secretaria de Politicas para as Mulheres, 2013b.

BRANDÃO, M. Marketing digital e redes sociais: um estudo de caso na formação de mulheres empreendedoras da Economia Solidária no Estado 
Piauí. 2016. Dissertação (Mestrado em Tecnologia e Gestão em Educação a Distância) - Universidade Federal Rural de Pernambuco, Recife, 2016.

BRUSCHINI, M. C. A.; RICOLDI, M. A.; MERCADO, M. C.; Trabalho e gênero no Brasil até 2005: uma comparação regional. Mercado de Trabalho e gênero: comparações internacionais. Rio de Janeiro: Editora FGV, 2008.

BRUSCHINI, M.C.A; LOMBARDI, M. R. Capitulo suplementar: Mulheres e homens no mercado de trabalho brasileiro: um retrato dos anos 1990 . As novas fronteiras da desigualdade: homens e mulheres no mercado de trabalho; Cleivi Rapkieviez (tradutora).-São Paulo: Editora Senac. São Paulo,2003.

CIELO, Ivanete Daga. Perfil do empreendedor: uma investigação das características empreendedoras nas empresas de pequena dimensão. UFSC, Florianópolis, 2001.

COSTA, C.da. O empreendedor no Brasil. Administradores, [s. \],23 mar.2011.Disponivel em:http://www.administradores.com.br/artigos/ ascaracteristicas-e-o-perfil-do-empreendedor/24327/Acesso em:18 maio 2021.

CRAMER, L. et al. Representações femininas da ação empreendedora: uma análise da trajetória das mulheres no mundo dos negócios. Revista de Empreendedorismo e Gestão de Pequenas Empresas, São Paulo, v.1, n.1, 53-71, jan./abril, 2012. GEM - GLOBAL.

DA SILVA, Mariana Santos; LASSO, Sarah Venturim; MAINARDES, Emerson Wagner. Características do empreendedorismo feminino no Brasil. Revista Gestão e Desenvolvimento, v. 13, n. 2, p. 150-167, 2016.

DE CAMARGO, Denise et al. O significado da atividade empreendedora: as práticas da mulher brasileira em 2008. Empreendedorismo e estratégia de empresas de pequeno porte 3Es2Ps, p. 105, 2010.

GITAHY, Yuri. O que é uma startup? 2011. Disponivel em: http://www. empreendedoronline.net.br/o-que-e-uma-startup/. Acesso em: 12 maio 2021.

HINI, M. C. A; LOMBARDI, M. R. Capítulo suplementar: Mulheres e homens no mercado de trabalho brasileiro: um retrato dos anos 1990. As novas 
Fronteiras da desigualdade: homens e mulheres no mercado de trabalho; Clevi Rapkieviez (tradutora). São Paulo: Editora Senac São Paulo, 2003.

DOLABELA, F. C. O segredo de Luísa: uma idéia, uma paixão e um plano de negócios: como nasce o empreendedor e se cria uma empresa. 13. São Paulo: Cultura, 2002.

DORNELAS, José Carlos Assis. Planejando incubadoras de empresas. Rio de Janeiro: Campus, 2002.

DORNELAS, Jose Carlos Assis. Empreendedorismo: transformando idéias em negócios. Rio de Janeiro: Elservier, 2008.

DRUCKER, P.F. Inovação e Espirito Empreendedor. Tradução de Carlos Malferrari. 6. ed. São Paulo, Pioneira Thompson, 2002.

ETHOS, Instituto. O Compromisso das empresas com a valorização da mulher. São Paulo: Instituto Ethos, 2004.

FERNANDES, Alves. União Estável e o Contrato Social de Startup.2020. Disponivel em : <https://alvesfernandes.com/blog/unio-estvel-e-ocontrato-social-da-startup>Acesso em: 21 maio 2021.

FIALHO, F. A. P. Empreendedorismo na era do conhecimento. Florianópolis: Visual Books, 2006.

FILLION, L. J. Empreendedorismo: empreendedores e proprietáriosgerentes de pequenos negócios. Revista de Administração. São Paulo, v.34, n.2, abr./jun. 1999.

FRANÇA, Ana Letícia de; SCHIMANSKI, Édina. Mulher, trabalho e família: uma análise da dupla jornada de trabalho feminina e seus reflexos no âmbito familiar. Ponta Grossa: Emancipação, 2009. Disponivel em: <http://www. uepg.br/emancipacao>. Acesso em: 22 jan. 2014.

FRANCO, Michele Maria Silva. Empreendedorismo Feminino: Caracteristicas Empreendedoras das Mulheres na Gestão das Micro e Pequenas Empresas. Goiânia: VIIIEGEPE, 2014. 
GARTNER, W. B. What are wet al king about whenwe talk about entrepreneurship? Journal of Business Venturing, v. 5, n. 1, p. 15-28, 1990.

GEM- GLOBAL ENTREPRENEURSHIP MONITOR. Empreendedorismo no Brasil - 2010. Curitiba: IBQP, 2010.

GOMES, A. F.; SANTANA, W. G. P. (2004). As habilidades de relacionamento interpessoal de mulheres que trabalham por conta própria: o caso de Vitória da Conquista-BA. In: Anais do Seminário de Administração (Semead), São Paulo, SP, Brasil, 7, 2004.

HILÁRIO, Giuseppe Neto. Diagnóstico e análise do perfil do empreendedor joseense. Taubaté: Universidade de Taubaté, 2004.

IBGE:https: / / agenciadenoticias.ibge.gov.br/agencia-sala-deimprensa/2013-agencia-de-noticias/releases/20232-estatisticas-degenero-responsabilidade-por-afazeres-afeta-insercao-das-mulheres-nomercado-de-trabalho. Acesso em: 02 jun. 2021.

IBGE:https: / / agenciadenoticias.ibge.gov.br/agencia-noticias / 2012agencia-de-noticias / noticias / 20287-no-dia-da-mulher-estatisticas-sobretrabalho-mostram-desigualdade. Acesso em: 02 jun. 2021.

ITABORAÍ, Nathalie Reis. Trabalho Feminino e Mudanças nas Famílias no Brasil (1976-2012): uma perspectiva de classe e gênero. Niterói | v.16 | n.2 | p. 173 - 199 | 1 | 1.sem. 2016.

JONATHAN, E. G. (2001). Mulheres empreendedoras: quebrando alguns tabus. Em III Encontro Nacional de Empreendedorismo (ENEMPRE). Anais do Encontro. Florianópolis: USFC (CD-ROM).

JONATHAN, E.G. Empreendedorismo: medos, conquistas e qualidade de vida. Psicologia em Estudo, v.10,n.3, p.373-3882, 2005.

JONATHAN, Eva G. Mulheres empreendedoras: o desafio da escolha do empreendedorismo e o exercício do poder. Psicologia Clínica, v. 23, n. 1, p. 65-85, 2011.

LEAL, Adriana Pinheiro. A Importância do Empreendedorismo para o Desenvolvimento Econômico no Brasil. Revista Cientifica Multidisciplinar 
Núcleo do Conhecimento. Ano 03, Ed. 08, Vol. 01, pp. 115-135, Agosto de 2018. ISSN:2448-0959.

LOCATELLI, Débora Regina Schneider. Impactos da pandemia da COVID-19 nos negócios: Percepções iniciais dos empreendedores. ENGEMA,2020. Disponivel em: <http://engemausp.submissão.com.br/22/anais / arquios/400.pdf. Acesso em: 20 jun. 2021.

LOIOLA, Camila Coutinho. Mulher empreendedora: dificuldades e preconceitos. Trabalho de Conclusão de Curso). Pontifícia Universidade Católica, Rio de Janeiro, RJ, Brasil, 2016.

MACHADO, Hilka Vier et al. O processo de criação de empresas por mulheres. RAE eletrônica, v. 2, n. 2, p. 0-0, 2003.

MARCONE, Marina de Andrade; LAKATOS, Eva Maria. Técnicas de Pesquisa. 5. ed. São Paulo: Atlas, 2002.

MARCONE, Marina de Andrade; LAKATOS, Eva Maria. Técnicas de Pesquisa. 7. ed. São Paulo: Atlas, 2010.

MESQUITA, Eduardo Pitombo. As caracteristicas do empreendedor nacional: o perfil comportamental de sucesso. Tese de Doutorado, 2016.

MOREIRA, Tayane Miranda. Empreendedorismo feminino, maternidade e conflito trabalho-familia. Rio de Janeiro, 2018.

NEGRISOLI,Mário Henrique Miranda; SOUZA, Flávio Jorge. Os desafios da gestão das pequenas empresas no pós pandemia:dificuldades $x$ oportunidades e mudanças. Conselho Regional de Administração do Pará,2020. Disponivel em:<http://cra-pr.org.br/70633-2/.Acesso em: 20 maio 2021.

NOGUEIRA, Claudia Mazzei. As Relações Sociais de Gênero no Trabalho e na Reprodução. Aurora, ano IV número 6- 2010 ISSN: 1982-8004

NOGUEIRA, M. Claudia. A feminização no mundo do trabalho: entre a emancipação e a precarização. O Avesso do Trabalho. 2.ed. São Paulo: Expresso Popular, 2010. 
PASSOS, Luana. Conciliação entre trabalho e família e individualização das mulheres brasileiras. Niterói.| v.16 | n.1 | p. 107 - 132 | $2 . \operatorname{sem} 2015$.

PEREIRA, Anete Marília et al. Cidade média e região: o significado de Montes Claros no norte de Minas Gerais. UFU, 2007.

PORTER, M. E. A vantagem competitiva das nações. Rio de Janeiro: Campus, 1992.

PROBST, Elisiana Renata; RAMOS, Paulo. A evolução da mulher no mercado de trabalho. Santa Catarina: Instituto Catarinense de Pós-Graduação, p. 1-8, 2003.

ROCHA,Coutinho, M. L. (2003). Quando o executivo é uma dama: a mulher, a carreira e as relações familiares. In: Féres-Carneiro, T. (org.). Família e casal: arranjos e demandas contemporâneas (p. 57-77). Rio de Janeiro: Editora PUC-Rio/Loyola.

RODRIGUES, L. de C. Ávila; JOIA, F. da S.; BORGES, D. G.; ANDRADE, J.M. Empreendedorismo feminino: estudo sobre características, desafios e perfis de gestão de micro e pequenos empreendedores no Município de Monte Belo-MG. Pesquisa, Sociedade e Desenvolvimento, [S. 1.], v. 10, n. 3, p. e28810313244, 2021. DOI: 10.33448/rsd-v10i3.13244. Disponivel em: https://rsdjournal.org/index.php/rsd/article/view/13244. Acesso em: 21 maio 2021.

SANTOS, Cintia Batista dos Renata et al. Empreendedorismo feminino: um estudo de caso sobre as razões empreendedoras no município de João Pinheiro. Revista eletrônica e cosmopolita em ação. Minas Gerais, 2020.

SCHNEIDER, Elton Ivan. A caminhada empreendedora: a jornada de transformação de sonhos em realidade. [livro eletrônico]/ Elton Ivan Schneider, Henrique José Castelo Branco. - Curitiba: InterSaberes, 2012.

SCHUMPETER, Joseph. The Theory of Economic Devefopment. Oxford. Oxford University Press, 1978.

SEBRAE. Os donos de negócio no Brasil: análise por sexo (20032013). 2015. Disponivel em:<http://www.bibliotecas.sebrae. com.br/chronus / ARQUIVOS_CHRONUS/bds/bds.nsf/4b813ba 67e266bbdc48177dd04726c87/\$File/5452.pdf > Acesso em: 01 abr. 2021. 
SEBRAE: ht t p s:// bibliotecas.sebrae.com.br/ chron u s / A R Q I V O S C H R O U S / b d s / b d s.n s f / b78f1023076077101d3baf93cf1efa06/\$File/5420.pdf Acesso em: 01 abr. 2021.

SEBRAE:http://www.sebrae.com.br/Sebrae/Portal\%20Sebrae/Anexos / GEM-Brasil-2008.pdf >. Acesso em: 01 abr. 2021.

SEBRAE:https://www.sebrae.com.br/sites / PortalSebrae/sebraeaz/ conheca-a-forca-feminina-no-universo-empreendedor,dc7c08cd17c90710 VgnVCM1000004c00210aRCRD. Acesso em: 01 abr. 2021.

SEN, Amartya Kumar. Desenvolvimento como liberdade. São Paulo: Companhia das Letras, 2000.

SILVA, Anna Carolina Aguiar da. Perfil Empreendedor :As principais características e os tipos de um empreendedor de sucesso.Brasilia, 2014.

SILVA, R. R. Mulheres empreendedoras: das dificuldades as conquistas no mundo dos negócios. (2007) Disponivel em: <http://www.administradores. com.br/_resources / files /_modules / academics / academics_663_2 01002281825025400.pdf >. Acesso em: 01 abr. 2021.

SIQUEIRA, D. P.; SAMPARO, A. J. F. OS DIREITOS DA MULHER NO MERCADO DE TRABALHO: DA DISCRIMINAÇÃO DE GÊNERO À LUTA PELA IGUALDADE. Revista Direito em Debate, [S. l.], v. 26, n. 48, p. 287325, 2017. DOI: 10.21527/2176-6622.2017.48.287-325. Disponivel em: https://www.revistas.unijui.edu.br/index.php/revistadireitoemdebate/ article/view/7233. Acesso em: 21 maio 2021.

SOUZA, Eda C. L. Empreendedorismo: da gênesis a contemporaneidade. In: Souza, Eda C. L e Guimarães, T de A., Org. Empreendedorismo além do plano de negócio. São Paulo: Atlas, 2005.

SOUZA, Sabrina Kelly Gomes de et al. Vivências de Prazer e Sofrimento no Trabalho na Percepção de Profissionais de Recursos Humanos. Revista de Empreendedorismo, Inovação e Tecnologia. Passo Fundo, v. 4, n. 2, p. 3-29, dez. 2017. ISSN 2359-3539. Disponivel em: https://seer.imed.edu. br/index.php/revistasi/article/view/2020/1709. Acesso em: 30 abr. 2021. doi:https:/ /doi.org/10.18256/2359-3539.2017.v4i2.2020. 
STEVENSON, Howard; GUMPERT, David. O coração do empreendedorismo. 1985.

STROBINO, Maria Regina de Campos; TEIXEIRA, Rivanda Meira. Empreendedorismo feminino e o conflito trabalho família: estudo de multicasos no setor de comércio de material de construção da cidade de Curitiba. São Paulo, v. 49, n.1. p. 59-71, jan/mar. 2014. ISSN0080-2107

TEIXEIRA, Rivanda Meira; BONFIM, Lea Cristina Silva. Empreendedorismo feminino e os desafios enfrentados pelas empreendedoras para conciliar os conflitos trabalho e família: estudo de casos múltiplos em agências de viagens. Revista Brasileira de Pesquisa em Turismo. v. 10 n. 1 (2016): janeiro/abril. Disponivel em: https://doi.org/10.7784/rbtur.v10i1.855. Acesso em: 20 maio 2021.

TIMÓTEO, Carolina Q. As transformações do movimento feminista no Brasil e sua relação com a América Latina. Disponivel em: < http://www.uel.br/ grupopesquisa/gepal/v7_carolina_GVII.pdf

VERGARA, Sylvia Constant. Projetos e Relatórios de Pesquisa em Administração. 2. ed. São Paulo: Atlas, 1998.

VICENTE, Teresa Aracena. As mulheres e seus tempos: dupla jornada de trabalho, cuidado de si e lazer na promoção da saúde. São Paulo, 2018. Disponivel em: https://www.teses.usp.br/teses/disponiveis/5/5137/ tde-02082018-103012/publico/TeresaAracenaVicente.pdf. Acesso em: 02 maio 2021.

WELSH, Dianne HB et al. Saudi women entrepreneurs: a growing economic segment. Journal of Business Research, v. 67, n. 5, p. 758-762, 2014.

WISSMANN, Alexandre Dal Molin; LEAL, Anne Pinheiro. Experiências de Microempreendedorismo Individual (MEI) na ótica das Relações de Trabalho no Município de Rio Grande-RS. Revista Livre de Sustentabilidade e Empreendedorismo, v. 3, n. 2, p. 5-19, 2018. 


\section{NORMAS PARA APRESENTAÇÃO DE ORIGINAIS}

\section{Informações gerais}

A Revista ECONOMIA E POLÍTICAS PÚBLICAS propõe-se a publicar trabalhos na área de economia, história econômica e políticas públicas, inéditos, em português, espanhol, inglês e francês, de autores da UNIMONTES ou outras Instituições na forma de:

. artigos;

. resenhas; Somente serão aceitas, quando houver, uma resenha, uma tradução, uma comunicação e uma entrevista em cada edição.

- traduções de artigos recentes (prazo de 2 anos da primeira publicação), de interesse relevante e acompanhadas de autorização do autor(es) e da revista em que o mesmo foi originalmente publicado; e

. Comunicações.

\section{Apresentação dos originais (PARA V.2.1 em diante)}

Os trabalhos deverão ser entregues em duas vias, constando apenas em uma delas a identificação do(s) autor(es), e em um CD; apresentados em letra 12, fonte Times New Roman, espaço um e meio, folha A4, margens $2,5 \mathrm{~cm}$, versão Word for Windows 7.0 ou inferior, de quinze a vinte laudas para os artigos e traduções, até cinco para as resenhas e três para as comunicações. A Revista aceita contribuições em fluxo continuo.

\section{Estrutura do trabalho}

Os artigos e traduções deverão obedecer à seguinte sequência:

. Título; (em português e em inglês)

- Nome do autor (somente em uma das cópias impressas) - deve vir à direita da página, acompanhado das referências acadêmicas do autor 
informadas em nota de rodapé.

. Resumo; (no máximo 200 palavras) (NECESSÁRIO EM TRÊS IDIOMAS, obrigatoriamente português e ingles, o outro a escolha, preferencialmente espanhol)

. Palavras-chave;

. Abstract;

. Keyword;

. Resumen;

. Palabras clave

. Texto - usar para as citações, bem como para as referências a autores, o sistema autor-data de acordo com as atuais normas da ABNT;

- Citação textual (caso haja) - até três linhas devem ser colocadas no corpo do texto entre aspas; com mais de três linhas devem vir destacadas do texto, em espaço simples;

- Notas de rodapé (caso haja) - devem ser colocadas ao pé da página. As remissões para o rodapé devem ser feitas por números, na entrelinha superior;

- Tabelas, gráficos e figuras (caso hajam) - devem ser numeradas consecutivamente, encabeçadas por título e conter legenda informando a fonte;

. Fórmulas matemáticas, quando indispensáveis, deverão ser digitadas no próprio texto e numeradas sequencialmente.

- Referências Bibliográficas - somente as que constarem do corpo do texto, de acordo com as normas ABNT/última versão.

As resenhas e comunicações dispensam o resumo e palvras-chave.

Obs.: Trabalhos entregues fora das normas ou sem revisão de português (de responsabilidade do autor) não serão analisados.

\section{Da publicação}

Os textos entregues à publicação serão apreciados por pareceristas anônimos: membros do Conselho Consultivo e professores do corpo docente da UNIMONTES ou de outra Instituição Universitária (especialista no tema proposto pelo artigo, desde que não seja o autor do mesmo), convidado para este fim. 
Os textos voltarão aos autores caso seja necessário alguma alteração. Para tais casos, o trabalho final deverá ser novamente entregue em duas vias e em um disquete, de acordo com as normas informadas anteriormente. A Comissão Editorial, baseada nos pareceres recebidos, selecionará os trabalhos que serão publicados; os que não forem selecionados podem ser retirados pelo autor no Departamento de Economia da UNIMONTES, ou requisitados por correspondência, no prazo de 02 (dois) meses após o recebimento do parecer. Após tal prazo os mesmos serão destruídos.

\section{Critérios de Seleção}

. Escolha do tema, no caso de edições temáticas.

. Relevância do tema

. Coerência do artigo

Os trabalhos devem ser enviados para o Departamento de ECONOMIA da UNIMONTES.

\section{Endereço:}

Economia \& Políticas Públicas (Revista do Departamento de Economia) Universidade Estadual de Montes Claros - UNIMONTES

Campus Universitário "Prof. Darcy Ribeiro"

Centro de Ciências Sociais Aplicadas - Depto de Economia

Av. Dr. Rui Braga, s/n - Vila Mauricéia

39401-089 - Montes Claros - MG

\section{Direitos}

Os trabalhos publicados não serão remunerados em hipótese alguma

$\mathrm{O}$ (s) autor (es), ao submeterem o trabalho à análise, automaticamente cedem os direitos de publicação à Revista, em sua versão eletrônica. e/ou impressa (A revista também será impressa e depositada em algumas bibliotecas de referência)

Os autores dos trabalhos aprovados $N A \tilde{O}$ terão direito a qualquer 
exemplar da edição em que constar sua publicação, pois trata-se de versão eletrônica.

Serão aceitos trabalhos com, no máximo, três autores.

Todos os casos não previstos serão analisados e decididos pelo Conselho Editorial que, dentre outras atribuições, ficará encarregada de informar aos autores da possibilidade da publicação, contra os quais não caberá recurso. 